\title{
Time is money: Costing the impact of duration misperception in market prices
}

Tiejun $\mathrm{Ma}^{1}{ }^{*}$, Leilei Tang ${ }^{2}$, Frank McGroarty ${ }^{1}$, Ming-Chien Sung ${ }^{1}$ and Johnnie E.V Johnson ${ }^{1}$

${ }^{1}$ Centre for Risk Research, Southampton Business School, University of Southampton, Highfield, Southampton, SO17 1BJ, United Kingdom.

${ }^{2}$ Strathclyde Business School, University of Strathclyde, 199 Cathedral St, Glasgow G4 0QU, Scotland, United Kingdom

\{tiejun.ma, f.j.mcgroarty, m.sung, jej\}@soton.ac.uk; leilei.tang@strath.ac.uk *Corresponding author

\begin{abstract}
We explore whether, and to what extent, traders in a real world financial market, where participants' judgements are reportedly well calibrated, are subject to duration misperception. To achieve this, we examine duration misperception in the horserace betting market. We develop a two-stage algorithm to predict horses' winning probabilities that account for a duration-related factor that is known to affect horses' winning prospects. The algorithm adapts survival analysis and combines it with the conditional logit model. Using a dataset of 4736 horseraces and the lifetime career statistics of the 53295 horses running in these races, we demonstrate that prices fail to discount fully information related to duration since a horse's last win. We show that this failure is extremely costly, since a betting strategy based on the predictions arising from the model shows substantial profits $(932.5 \%$ and $16.27 \%$, with and without reinvestment of winnings, respectively). We discuss the important implications of duration neglect in the wider economy.
\end{abstract}

Highlights:

- Demonstrate existence of duration misperception in a real-world environment

- Develop a 2-stage forecasting model combining survival analysis \& conditional logit

- Employ survival analysis to study pricing efficiency in a speculative market

- Evaluate the economic costs of duration misperception in a financial market

Keywords: forecasting, economics, OR in sports, cognitive bias, sports betting. 


\section{Introduction}

Sterman (2000, p.26) observed that "faced with the overwhelming complexity of the realworld, time pressure, and limited cognitive capabilities, we are forced to fall back on rote procedures, habits, rules of thumb, and simple mental models to make decisions." One of the consequences is duration neglect, where the human brain reduces experiences to "peak-andend" events “... as if duration did not matter” (Frederickson \& Kahneman, 1993, p54).

In many fields, overlooking or incorrectly interpreting duration can lead decision makers to incorrect choices. In fact, the consequences of duration misperception in experimental studies are well known. For example, subjects have been found to underestimate the time-delay in repeated scheduling tasks (Sterman, 1989) and to underperform in tasks because of confusion linked to time delays and feedback loops (Sterman \& Diehl, 1993). Even experienced decision-makers have been shown to misallocate resources because they consistently confuse stock and flow variables, and misperceive how these relate to each other over time (Moxnes, 1998; Sweeney \& Sterman, 2000). The latter study, which involved mathematically trained MBA students, concluded that subjects misperceived time delays. Ossimitz (2002) found that duration-based stock-flow confusion resulted in subjects being no better at forecasting than a random coin-toss and Cronin and Gonzales (2007) attributed the stock-flow confusion phenomenon to overly-simple heuristics. Furthermore, $\mathrm{Fu}$ and Gonzales (2006) showed that including irrelevant information further adversely affected subjects' ability to estimate duration. The conclusion to emerge from these experimental studies is that subjects fail to account fully for duration information when making decisions. However, to our knowledge, whether individuals engaged in real world activities are subject to duration misperception and, if so, the impact it might have, has not been addressed. This, therefore, may have led decision makers to pay less attention to duration misperception than they should.

We examine a real world setting where one might expect duration to be considered carefully, namely, where there are large financial penalties associated with duration misperception. Clearly, if we discover duration misperception in such a setting it suggests this phenomenon is more widely prevalent and may cause significant pecuniary loss.

To achieve our objective, we search for duration misperception in an apparently efficient financial market. The semi-strong form of the Efficient Market Hypothesis (EMH) (Fama, 1970; Fama, 1991) states that, if a market is fully efficient, it should be impossible to 
find any publicly available information that can be systematically exploited for pecuniary gain. This is widely held by financial economists and Jensen (1978) claims that "there is no other proposition in economics which has more solid empirical evidence supporting it." Clearly, therefore, all publicly available information, including that related to duration, should be fully discounted in market prices. If this is not the case, this will represent an important discovery.

We focus on a speculative market, which previous studies have demonstrated incorporates efficiently a range of complex information (e.g., Bruce \& Johnson, 2000).and where large sums are traded; namely, the horserace betting market ( $\$ 134$ billion p.a. bet worldwide: International Federation of Horseracing Authorities, 2013). Speculative markets associated with sports, and the events on which they are based, have a definitive endpoint where all uncertainty is resolved. For example, at the end of a horserace, the winner is declared and uncertainty regarding the 'correct' prices (odds) is fully resolved (Peel, 2009). Consequently, speculative markets associated with sports events, and the events themselves, provide an ideal setting in which to measure the impact of biases (Law and Peel, 2002). For example, Hwang and Kim (2015) analyzed betting market data related to volleyball to test the degree to which bettors underestimate probabilities corresponding to extreme ends of the distribution and learning behaviour. Marginson (2010) examined the extent to which horserace bettors fully discount information held by insiders and Flores et al. (2012) showed that professional sport managers might make biased decisions due to public pressure. We conducted interviews with training and breeding experts in the racing industry to discover what they believed might be the most important duration factor that the betting public undervalues. This turned out to be the time that horses need to recover from winning performances. They argued that the betting public are likely to understand that horses need time to recover between races, as this is given considerable attention in the media. However, they believed that the betting public might not appreciate the significantly greater recovery time that is needed when horses have exerted maximum effort. Jockeys often do not push horses to their limits should they believe, as the race unfolds, that they do not have a clear winning chance. Therefore, the interviewees argued that the exertion of maximum effort by a horse is most reliably captured by focussing on winning performances and that the betting public are likely to fail to account for the time between a horse's winning performances. The interviews also revealed that a range of factors influence speed of recovery following winning performances, including, the horse's age, gender, length-of-distance-run, ability and general health. An individual horse's recovery state after a race is, therefore, a combination 
of the degree to which it exerted maximum effort in that race, its own speed of recovery and the time since that race. Based on our interviews, it is this complex cocktail of duration-based information for all competitors in a race that we suspect the betting public might struggle to estimate correctly.

Previous studies examining the forecasting accuracy of horserace betting markets suggest that market prices generally incorporate available information (e.g., Law \& Peel 2002, Vaughan Williams \& Paton, 1997). The few studies that generate forecasts of winning probabilities that can be used to earn abnormal returns only do so by combining a number of complex derivatives of raw variables associated with each horse and/or by capturing the complex non-linear relationships (Lessmann et al., 2010) or interactions between several variables (see Sung \& Johnson, 2008 for a review), including, for example, published forecasts from racing experts. However, individuals have been shown to be influenced by irrelevant factors when assessing the reliability of forecasts (e.g., Goodwin, 2005). Supplying additional information (e.g. prediction intervals) does not improve the quality of resulting decisions (Goodwin, et al., 2010) unless, in the case of prediction intervals, they are employed in the correct circumstances (Savelli and Joslyn, 2013; Ramos et al., 2013). This clearly cannot always be relied upon in any uncontrolled situation such as a horserace betting market. It has also been shown that judgmental adjustments to statistical forecasts can damage accuracy (Fildes et al., 2008). Horse race bettors' forecasts are largely based on judgement and it conceivable, we believe, that bettors may fail to fully employ durationbased information; specifically, the duration between a horse's winning performances (we refer to this period subsequently as, 'days between wins' (DBW).

Consequently, we explore to what extent information concerning DBW can significantly improve upon market-generated forecasts of winning probabilities. To achieve this we adapt survival analysis (SA), a statistical technique for analysing the time to the occurrence of an event, to the task of predicting winners of horseraces. Our adaptation captures the competitive relationship between horses in a race by developing a two-stage SA/conditional logit (CL) model. A horse's wins occur at well-defined points in time, and it is therefore possible, in stage one, to adopt SA to model the relationship between the individual horse's characteristics (e.g., gender and age), and the time to the occurrence of its next win. Conventional statistical methods, such as logistic regression, can only include time related information by incorporating suitable independent variables. Consequently, they are unable to incorporate information concerning time between events (e.g. DBW) directly within the underlying model using probabilities conditional on time. Logistic regression, 
therefore, does not use time-related information in the most efficient manner. On the other hand, survival models directly estimate the probability of $P(T \geq t)$, which can be interpreted as the probability that the time until an event occurs is larger than time $t$. The hazard rate in survival models allows the investigation of the probability distribution of the event's occurrence at time $t$ given it did not occur before time $t$.

In addition, logistic regression gives a discrete probability of the event occurring, regardless of the time of the event's occurrence, and these models do not have the capability of handling partial information. For example, logistic regression has no mechanism for directly using information concerning an event that has not yet occurred (e.g., the time since the last win of a horse until the end of the period covered by the dataset). Whereas, the Cox model would be able to use such partial information by using censoring techniques.

The transformation of event-based information for use in a SA model is complex and non-intuitive and we believe that it is beyond the ability of most bettors to interpret this information fully and correctly.

The second stage of our model employs CL to account explicitly for competitors' relative strengths when estimating winning probabilities (e.g. Bolton and Chapman, 1986). To the best of our knowledge, our two-stage model is the first attempt to combine SA with CL. It captures the impact of an individual competitor's characteristics on the time before they achieve their next win, as well as accounting for competition. This enables us to measure the impact of bettors failing to account for duration-based information, via the abnormal returns that predictions from such a model produce.

\section{Hypotheses and data}

\subsection{Hypotheses}

The key aim of this paper is to identify whether, and to what extent, duration misperception occurs in a real-world financial market. To achieve this we examine the degree to which the DBW is not fully discounted in the prices in what are widely regarded as efficient horserace betting markets. Sterman (1989) observes that individuals are particularly bad at interpreting information with a time dimension. Consequently, we believe that most bettors, whilst realising that the DBW is important when assessing winning probabilities, will attempt to account for it by applying inadequate, simplifying heuristics. Consequently, we test the following 'Duration Misperception Hypothesis': Bettors inadequately account for the time 
between a horse's winning races, to the extent that abnormal returns are possible by trading on predictions derived from a model that appropriately incorporates this information.

To develop an appropriate SA model to test this hypothesis, we identify a range of variables that we believe influence the DBW. Following informal interviews with racehorse trainers and breeders, we came to the view that the DBW will differ between horses, based on a number of factors related to their (a) physiology and (b) ability/fitness. Specifically, the interviews highlighted three potentially influential factors related to physiology that were likely to affect post-race recovery times: age, gender and distance of previous race. We also identified the following scientific evidence to support these views:

(i) Age: It is widely reported that racehorses need time to recover from general physical stresses and exercise-related injuries (Evans, 2007). There is also much evidence that recovery times are longer for older muscles (e.g., McBride et al., 1995) and, particularly relevant for DBW, older individuals take much longer to recover muscle strength after strenuous exercise (Dedrick \& Clarkson,1990). On the other hand, younger horses, due perhaps to under-developed bone or less controlled physical activity may be subject to more training injuries. In fact, Rossdale et al. (1985) found that two-year (cf. three-year) olds lose more training days due to lameness. Therefore, whilst the precise differences in recovery times after maximum exertion for different aged horses may be unclear, it is likely that DBW will vary with age.

(ii) Gender: Recovery times since a winning performance for males and females are likely to be different. Clark et al. (2003) found that there is a 33\% difference in muscular endurance capacity between males and females and a number of studies have found differences in the recovery time of males and females (Fulco et. al., 1999; Russ \& KentBraun, 2003; Russ et al., 2005; Hunter et al., 2006). Therefore, when modelling competitive events such as horse races, we would expect gender to affect DBW.

(iii) The length of previous races: Rooney (1982) found that "horses experience greater fatigue lameness and bone fracture-breakdown at certain race distances" and so will require longer recovery times. Those horses that run in short (cf. longer) distance races generally expend less energy; sprinters are therefore likely to recover more quickly. Furthermore, Kellmann (2002, p19) emphasises that adequate rest and recovery is crucial, especially after exerting maximum effort. Both under-recovery and over-training would result in reduced performance and these periods will vary with previous race distance. 
Our discussions with racehorse trainers and breeders also led us to the view that a horse's ability and fitness are likely to influence the DBW. In particular, they identified the following three ability/fitness related variables that might influence DBW:

(iv) Previous race odds-implied-win-probability: Horses that the betting public judged to have had a good chance of winning their previous race are likely to be associated with a shorter time to their next win. This may arise because the betting public are likely to judge a horse's chances as good if they look fit and in good health. In addition, horses cannot maintain maximum fitness for prolonged periods. Consequently, horses which looked fit prior to their previous race and whose prior performances pointed to them having a good chance in that race are likely to be placed by their trainers to win races in quick succession whilst they maintain that fitness. DBW are expected, therefore, to be lower for horses with higher odds-implied-win-probability in their previous race.

(v) Cumulative prize money: Horses that have demonstrated their ability to perform well in many races and/or in good quality races (as evidenced by their accumulated prize money to date) are likely to be associated with a shorter DBW. This arises because of their innate ability and resilience (i.e. their ability to recover from the rigours of racing), which they have demonstrated in previous performances.

(vi) Number of losing races since last win: This variable will contain information regarding a horse's win/lose ratio and Ceaser and Busch (1997) found that in competitive events, there is a relationship between previous losses and future winning chances. For horses, the win/lose ratio is regarded as a sign of the horse's ability, less losing runs between wins suggesting greater ability. Conversely, horses may maintain racing fitness better by running in competitive races than they can on the training gallops. If this is the case, then horses with more losing races since their previous win might have shorter DBW. Whilst the direction of influence of this variable is unclear, our interviews led us to believe that because we will already be accounting for a horse's ability via factors (iv) and (v) above, the horse's racing fitness derived from losing runs may reduce DBW.

In order to determine which of the physiological and ability/fitness factors impact the DBW and which, therefore, may be neglected in the betting price, we test the following 'Horse Physiological/Ability/Fitness Hypotheses': The time until a horse's next win (since its previous win or from the commencement of its career if it has not yet won) will vary with: (i) its age, (ii) its gender, (iii)the distance of its previous race, (iv) its odds-implied-winprobability in its previous race, (v) its cumulative career prize money prior to its current race and (vi) number of losing races since its last win. 


\subsection{Data description}

Bettors in horserace betting markets purchase assets (i.e. place bets), returns to which depend on the result of the race to which the market relates. The purchase price of a claim on horse $i$ in race $j$ which pays $\$ 1$ if horse $i$ wins and nothing if it loses, is given by $1 /\left(1+O_{i j}\right)$, where $O_{i j}$ represents horse $i$ 's market price or 'odds'. The mechanism by which the odds are set depends on the type of betting market.

We set a tough benchmark to ensure that duration neglect truly exists by employing data from the bookmaker market. The final odds in these markets have been shown to be efficient in a number of studies (Vaughan Williams, 1999). There are two key reasons for this, the first related to the bookmakers themselves and the second related to the bettors who are attracted to bet in these markets. In particular, bookmakers operate at racetracks and in high street betting offices and are respected for their access to a range of sophisticated sources regarding competitors' chances of success (Levitt, 2004). Bookmakers offer fixed odds (i.e. bets are settled at the odds prevailing at the time the bets are struck) and these partly reflect their sophisticated judgments and the information they have gathered. They post odds at the start of the market for a given race and subsequently change these odds as a result of receiving information concerning horses' prospects and/or as a result of demand for bets. It is well established that informed traders are more likely to bet with bookmakers in the UK than with the parallel pari-mutuel market. There are a number of reasons for this. The first is that they will wish to secure their return (by betting at odds fixed at the time they place their bet) without the danger of a herding effect eroding their gains (Sauer, 1998; Schnytzer and Shilony, 1995). In the pari-mutuel market, a pool of bets is formed and the odds are determined by the relative amounts bet on each horse, bets being settled at the odds prevailing at the close of the market. Consequently, in the pari-mutuel market, herding could erode the gains an informed bettor had expected. In addition, the pari-mutuel market is relatively small (approximately $2.5 \%$ of the turnover of UK bookmaker market), and this prevents informed bettors placing the large bets they may wish to make.

Consequently, in order to set a testing benchmark for assessing whether sophisticated forecasts that incorporate information concerning DBW can be used to earn abnormal profits, we employ odds developed in the UK bookmaker market. In particular, we employ the final prices prevailing when the race starts. These odds are used as informed traders often bet late in the market (Crafts, 1985) in order to ensure that they maximise their exposure to information related to a horse's chance of success (e.g., how well a horse gallops to the start). 
In fact, a number of studies demonstrate that valuable information is revealed throughout the course of the market (e.g. Dowie, 2003; Schnytzer and Shilony, 2002; Schnytzer et al., 2003). The final odds are, therefore, the most likely to incorporate all the information to which bettors (including informed bettors) are exposed and represent the combined knowledge of the sophisticated bookmakers and bettors.

\subsubsection{Data source and characteristics}

We obtained our data from Raceform Interactive, one of the most respected providers of horseracing data in the UK. The data includes details of flat races run in the UK in the 2005 season (1st Jan 2005- 5th Nov. 2005) ${ }^{1}$ : 4736 races, with 53295 runners. We examine the past running history for each horse in the dataset, the longest of these dating back to 7th January 1996 (24,854 races with 296,475 runners). We select 5th November 2005 as our survey date as it is the end date of the 2005 season, beyond which no races were considered i.e., the rightcensoring date. The maximum number of wins of a horse through its entire career was 22 and among those that did win, the mean and maximum period a horse waited to win (either between wins, or from the start of its career to its first win) were 157 days (Standard Deviation (S.D.) = 172 days) and 1628 days, respectively. In addition, the mean number of wins among winning horses over the sample period to 5th November 2005, was 2.81 (S.D. = 2.45). Summary statistics for the days between wins and the number of wins per horse, over a horse's career to 5th November 2005, for all horses which had at least one win in their career, are given in Table 2.1 .

\begin{tabular}{|c|c|c|}
\hline \multicolumn{3}{|c|}{$\begin{array}{l}\text { ran } \\
\text { n at }\end{array}$} \\
\hline Statistics & Days between consecutive wins & Number of wins \\
\hline Mean & 157.36 & 2.81 \\
\hline S.D. & 172.49 & 2.45 \\
\hline 25 th percentile & 32 & 1 \\
\hline Median & 104 & 2 \\
\hline 75th percentile & 220 & 4 \\
\hline Minimum & 1 & 1 \\
\hline Maximum & 1628 & 22 \\
\hline
\end{tabular}

eve that factors related to a horse's physiology, ability and fitness are likely to affect the DBW. Consequently, the relevant descriptive statistics concerning these factors for DBW for horses with at least one win in their career are displayed in Tables 2.2a and 2.2b. To simplify this analysis, we create binary variables for a horse's age $(\leq 2$ years= "young", $>2$ years = 
"old") and gender (male (colts, geldings or stallions) vs. female (fillies and mares)) and races ( $\leq 1540$ yards $=$ "sprint", $>1540$ yards= "long distance"). In addition, we also provide statistics for the DBW for horses grouped on the basis of (a) their previous prize money (b) the odds in their previous race and (c) the number of losing races since their last winning performance.

Table 2.2a: Days between wins, classified by factors believed to affect post-race recovery time

\begin{tabular}{lllllll}
\hline Statistic & \multicolumn{2}{l}{ Age of horse } & \multicolumn{2}{c}{ Gender of horse } & \multicolumn{2}{l}{$\begin{array}{l}\text { Distance of previous } \\
\text { race }\end{array}$} \\
\hline & Young & Old & Male & Female & Sprint & Long \\
$\begin{array}{l}\text { Mean } \\
\text { (days) }\end{array}$ & 52.32 & 178.80 & 139.30 & 161.80 & 141.74 & 170.80 \\
S.D. & 42.64 & 180.95 & 146.61 & 178.02 & 160.98 & 180.77 \\
\hline
\end{tabular}

Table 2.2b: Days between wins, classified by factors believed to be indicative of a horse's ability/fitness

\begin{tabular}{|c|c|c|c|c|c|c|}
\hline \multirow[t]{2}{*}{ Statistic } & \multicolumn{2}{|c|}{ Prize Money } & \multicolumn{2}{|c|}{ Previous Odds } & \multicolumn{2}{|c|}{$\begin{array}{l}\text { Number of losing races } \\
\text { since last win }\end{array}$} \\
\hline & $<$ median & $\geq$ median & $<$ median & $\geq$ median & $<$ median & $\geq$ median \\
\hline $\begin{array}{l}\text { Mean } \\
\text { (days) }\end{array}$ & 180.67 & 148.30 & 116.53 & 206.61 & 106.20 & 219.01 \\
\hline S.D. & 226.28 & 200.18 & 162.75 & 243.21 & 166.23 & 238.40 \\
\hline
\end{tabular}

From Table 2.2a and 2.2b, we can clearly see that there are substantial variations in horses' DBW for each factor group (e.g., young and old horses have average DBW of 52.32 and 178.80, respectively). Therefore, we aim to capture the manner in which these factors affect the DBW using a suitable multivariate regression technique. In particular, we employ Survival Analysis (SA), since it provides an ideal methodology for estimating the conditional probability of the next winning event in a given time period, accounting for the range of factors we consider important, as explanatory variables. The closeness of the means and standard deviations of the independent variables shown in Table 2.2a suggests that these variables may follow exponential distributions. This does not undermine the modelling process we propose since the Cox model is designed to handle independent variables (including dummy variables) which follow any distribution and no assumption is made as to the underlying event times (Cox, 1972).

The predictions from our SA model, combined with the incorporation of competitiveness within a race (see Section 3.3) enable us to produce predictions of winning probabilities. We employ these probabilities as inputs to betting models (see Section 4), 
which allow us assess whether information concerning DBW can be used to make abnormal returns. If such returns are possible, it will signal duration neglect.

\section{Methodology}

\subsection{Survival Analysis}

The key principles of SA are summarised in Klein and Moeschberger (2003). SA has been successfully employed in many areas to improve forecasts related to the duration between events, including the timing of events such as death or recurrence of illness (e.g., Willett \& Singer, 1995). In addition, SA has been applied across many fields to study the interval between or before various events. For example, SA has been employed to make effective forecasts in political science (Box-Steffensmeier \& Jones, 1998; Bennett, 1999), demography (Smith \& Zick, 1994) and economics (Meyer, 1990; Dolton \& Van der Klaauw, 1995; Bloemen \& Kalwij, 2001). SA has also been applied in finance, for example, to predict mutual funds' hazard rates of closure (Lunde et al., 1999), the impact on credit availability of the length of a firm's relationship with its bank (Ongena \& Smith, 2001), the survival of new franchisors (Shane \& Foo, 1999) and the timing of consumers' purchases (Kamakura et al., 2004). Therefore, SA is an ideal tool for examining duration neglect as it provides a means of analysing data when the result of interest is duration until the occurrence of some particular event.

SA allows the investigation of the probability distribution of the event's occurrence at time $t$ given it did not occur before $t$. In a horserace context, a race $j$ will normally last less than a few minutes $\left(T_{\mathrm{r}}\right)$ and the time between two races $j$ and $j+1$ or the time between two wins for the same horse $i, T_{b r}$ is normally at least two days. As $T_{r} \ll T_{b r}$, a race or winning event for a horse can be regarded as an instantaneous event. This simplifies our adaptation of SA.

The semi-parametric model developed by Cox (1972) (referred to as the Cox PHM), for modelling the events of interest occurring at time $t$ conditional on that event having not occurred before $t$, is suitable for our purposes because it avoids making inappropriate assumptions concerning the probability distribution of the time between a horse's winning performances. In addition, it is a powerful multiplicative regression model and has been successfully adopted in many domains for time based event modelling (e.g., to analyse bank failures (Lane et al., 1986) and system downtime failure events (Li et al., 2007)). Cox PHM 
can handle time-dependent variables, which in a horserace context include characteristics of individual horses that change in value in subsequent races, such as age. These features make the Cox PHM a useful tool for capturing relationships among time, explanatory variables and winning events in horseraces.

Moreover, the Cox model and its extensions, have been widely adopted to handle repeated events with correlation. We adopt Cox PHM to model the relationship between a horse's characteristics and DBW. We employ an extension of the Cox PHM to handle the fact that horses can win multiple races throughout their career. There are various extensions of the original Cox model and a detailed comparative discussion about handling heterogeneity and event dependence using extended cox models is provided in Box-Steffensmeier et al. (2006). Wei et al. (1989), Andersen and Gill (1982) and Prentice et al. (1981), have all suggested extensions to handle such repeated events. Specifically, they handle situations involving heterogeneity across individuals (e.g. some individuals have a higher or lower event rate than others due to their different characteristics and other unknown effects) and/or involving dependence across the number of events (e.g. the occurrence of one event, such as winning, may make future similar events more or less likely). These extended Cox models for repeated events have been successfully employed in a variety of situations, such as reliability engineering ( $\mathrm{Li}$ et al., 2007), medical studies, including the modelling of various types of recurrent illness (Willett and Singer, 1995; Cook et al., 1999;) and in modelling repeated political events (Bennett, 1999; Box- Steffensmeier and Zorn, 2002).

The model we employ is based on the model for repeated events with correlation developed by Prentice et al. (1981). This stratifies the data by event, so that the baseline hazard is allowed to vary with each event. Conditional models are estimated in elapsed time or in gap time and cases are designated at risk for event k only after experiencing the (k-1)th event. We use this model because horses remain the 'same individual' throughout their career but there is heterogeneity among horses (e.g. they have different characteristics, such as different recovery times between races). In addition, the chance of a horse winning a future race may well depend on factors related to its previous wins (e.g., whether the race is run on the same surface (turf vs sand)). As discussed above, previous studies have shown that the type of model that we employ is appropriate for handling such situations. In addition, multiple wins of the same horse implies a sequential order (e.g. a kth win may only occur after the (k-1)th win) and the Prentice et al. (1981)'s model caters for sequential order of events (Box-Steffensmeier \& Zorn, 2002), whilst allowing for multiple 'events' in a specified time interval. 


\subsection{Duration between horses' winning performances modelled using survival analysis}

We model horse $i$ 's career from race 1 , run at time $t_{1}$. Horse $i$ 's first win is assumed to occur in race $x$ at time $t_{x}$, and $k_{i}$ counts the number of its career wins up to and including race $x$ (e.g. $k_{i}=1$ at $t_{x}$ ). If horse $i$ wins race $j$ (with $n_{j}$ runners), then $k_{i}$ increases by 1 . With such a timeline-based definition $\left(t_{x}, k_{i}\right)$, our collected data for all runners in $y$ races represents a sample of $n$ observations ( $n=\sum_{1}^{y} n_{j}$ ). For horse $i$, the probability it wins a race at time $T_{i}$, is noted as $P\left(E_{i}\right)$, if $E_{i}$ denotes the winning event of horse $i$. If horse $i$ does not win any race before the censor date (i.e. 5th November 2005), noted as $t_{\mathrm{c}}$, we call it right censored time, which means that $T_{i}$ will occur at some time after $t_{\mathrm{c}}, T_{i} \in\left(t_{\mathrm{c}},+\infty\right)$.

We adapt this model to predict the probability $P\left(E_{i}\right)$ of the next 'win' occurring for horse $i$ in race $j$ at time $t$, under the condition that such a win does not occur before time $t$, i.e. $P_{i}\left(t+\Delta t>T_{i} \geq t \mid T_{i} \geq t\right)$.

Cox (1972) proposed the following form for the hazard function, $h(t)$, at time $t$ :

$$
h\left(t ; Z_{i}(t)\right)=\exp \left(\boldsymbol{Z}_{\boldsymbol{i}}(\boldsymbol{t}) \boldsymbol{\alpha}^{\boldsymbol{T}}\right) h_{0}(t),
$$

where $\boldsymbol{\alpha}$ is a $1 \times m$ vector of regression parameters ( $m$ is the number of explanatory covariates), " $\boldsymbol{T}$ " denotes the transpose of the vector, covariate $\boldsymbol{Z}_{\boldsymbol{i}}(\boldsymbol{t})$ is any quantity recorded in respect of each horse, such as age and gender and $h_{0}(t)$ is the baseline hazard, intended to capture the basic rate in the hazard when $\boldsymbol{Z}_{\boldsymbol{i}}(\boldsymbol{t})$ equals zero. In the hazard function, $\boldsymbol{\alpha}$ measures the impact of the explanatory covariates on the hazard rate. Through the scalar product, $\boldsymbol{Z}_{\boldsymbol{i}}(\boldsymbol{t}) \boldsymbol{\alpha}^{\boldsymbol{T}}$, the influence of each factor in $\boldsymbol{Z}_{\boldsymbol{i}}(\boldsymbol{t})$ enters the hazard multiplicatively. This model assumes that the hazard with covariates $\boldsymbol{Z}_{\boldsymbol{i}}(\boldsymbol{t})$ is proportional to its baseline hazard rate $h_{0}(t)$, the constant of proportionality being the exponential term $\exp \left(\boldsymbol{Z}_{\boldsymbol{i}}(\boldsymbol{t}) \boldsymbol{\alpha}^{\boldsymbol{T}}\right)$.

The hazard rate $h\left(t ; \boldsymbol{Z}_{\boldsymbol{i}}(\boldsymbol{t})\right)$, in our case, is the instantaneous probability of the horse winning at time $t$, conditional on the horse having not won before $t$. The horse's characteristics (e.g., age, gender) are included as explanatory covariates, $\boldsymbol{Z}_{\boldsymbol{i}}(\boldsymbol{t})$. Therefore, the outcome of this hazard analysis is the combination of an event (a race win), a duration between the moment the event became 'at risk' (i.e. a horse commenced its career or had its last win) and the date the event (a win) occurs or the right censoring date (i.e. 5th Nov. 2005), 
whichever is earlier. One advantage of applying the Cox PHM is that we do not have to estimate the baseline hazard $h_{0}(t)$ (see detail in Cox 1972). This avoids the potential bias of an inappropriate distribution assumption, and thus makes the model more flexible.

As described in the Section 2.1, we identify six factors that may affect the DBW: $v_{M}: 1$ if male; 0 otherwise;

$v_{O}(t)$ : the ' $\log$ of odds-implied probability of horse $i$ winning in its previous race $k$ ' (i.e $\log$ $\left.\left(1 /\left[1+O_{i k}\right]\right)\right)$, where $O_{i k}$ is the odds of horse $i$ in race $k$. (We employ this log transformation of the bookmakers' odds-implied probability because this captures the maximum information concerning winning probabilities contained in odds (e.g., Canfield et al., 1987). This arises from the fact that bookmaker odds generally over/under estimate the probability of low/high probability events (Ottaviani \& Sørensen, 2008) and the log transformation corrects for this anomaly);

$v_{Y}(t): 1$ if age $\leq 2$ years and 0 otherwise;

$v_{R}(t)$ : the number of races lost since the horse's last win or from its career start if no wins in career prior to today's race, $R=\{0,1,2,3 \ldots\}$;

$v_{S}(t): 1$ if previous race a 'sprint' (<1540 yards), and 0 if otherwise:

$v_{P}(t)$ : the horse's accumulated career prize money prior to today's race.

These six factors are included as a vector of covariates $\boldsymbol{Z}_{\boldsymbol{i}}(\boldsymbol{t})=\left[\boldsymbol{v}_{M}\right.$, $\left.v_{O}(t), v_{Y}(t), v_{R}(t), v_{S}(t), v_{p}(t)\right]$ in our Cox PHM model (see Eq. 2), where $v_{M}$ is independent of time $t$ and the remainder of the factors are time-dependent.

A horse will be 'at risk of winning' when it is entered for a race on given day. Therefore, we measure the time in days after a previous win. One issue with formulating this period is that it is possible to have event ties on the same day, and this is not directly allowed (e.g. multiple races/winning events for different horses or, very rarely, the same horse, on the same day) in the SA model. To tackle this problem, we adopt a discrete logistic transformation of the hazard function, introduced by Cox (1972) and adopted in Stepanova and Thomas (2002). With this discrete logistic transformation of the hazard function to solve event ties, we are able to calculate $P_{i}\left(t+\Delta t>T_{i} \geq t \mid T_{i} \geq t\right)$.

A further complication arises since a horse might win multiple races in its career. Consequently, we adapt the model to handle repeated wins by the same horse, using a counting process formulation (Prentice et al., 1981). A multivariable counting process $k=$ $\{k(t): 0 \leq t<+\infty, k(t) \leq \boldsymbol{K}\}$, is a stochastic process with non-decreasing integer values, with increments of size +1 , where $\boldsymbol{K}$ is the maximum number events for a subject $(\boldsymbol{K}<+\infty)$. 
In our case, $k_{i}$ counts the number of wins for horse $i$ by time $t$ (i.e. in $[0, t]$ ). Consequently, for horse $i$ we note $k$ as $k_{i}(t)$, which satisfies the model's criteria that $k_{i}(t)<+\infty$.

We are interested in the probability of horse $i$ winning in the period since its last win and the risk time interval is therefore defined as $\left[t_{k-1}, t_{k}\right)$. A horse is assumed to only be 'at risk' for the $k$ th winning event after the $(k-1)$ th winning event has occurred. This produces a conditional gap time (e.g., $\left.\left[t_{k-1}, t_{k}\right)\right)$ proportional hazard function with time dependent strata, where the dependence between successive wins for each horse is handled by stratifying by the number of previous wins.

We also adapt the vector of covariates of horse $i$ with respect to the $k t h$ win. Let $\boldsymbol{Z}_{\boldsymbol{i} \boldsymbol{k}}(t)$ be the vector of covariates for horse $i$ with respect to the $k$ th win. Therefore, based on the conditional model (Prentice et al. 1981, p374, Eq. (2)), the hazard function for horse $i$ for the $k$ th win has the following form:

$$
h_{i k}(t \mid k(t))=\left(t-t_{k-1}\right) \exp \left(\boldsymbol{Z}_{i k}(\boldsymbol{t}) \boldsymbol{\alpha}^{\boldsymbol{T}}\right) h_{0 k}(t)
$$

where $h_{0 k}(t)$ is the baseline hazard rate that varies by the time since a horse's last race. This equation incorporates a gap time data structure to explore the relationship between the explanatory covariates $\boldsymbol{Z}_{\boldsymbol{i k}}(t)$ and the hazard (i.e. the risk that the $k$ th win occurs for horse $i$ after its $(k-1)$ th win). We also employ a 'predictable process' $Y_{i k}(t)$, introduced by Anderson and Gill (1982, p1102), to indicate whether horse $i$ is 'at risk of winning' at a given time $t$ (i.e. is running in a race between its $(k-1)$ th and kth wins: in which case, $Y_{i k}(t)=1$, and 0 otherwise. Let $T_{i k}$ be the time until the $k$ th win for horse $i$ and $t_{s}^{i k}$ be the censoring time of horse $i$ for the $k$ th event, $t_{i k}=\min \left(T_{i k}, t_{s}^{i k}\right)$. The time between wins (gap-time) for horse $i$ is defined as $g_{i k}=t_{i k}-t_{i k-1}$ with $t_{i 0}=0$. Consequently, as shown in Prentice et al. (1981), the conditional probability $P_{i}\left(t+\Delta t>T_{i} \geq t \mid T_{i} \geq t\right)$ at time $t=t_{i k}$ is given by:

$$
\frac{\exp \left(\boldsymbol{Z}_{\boldsymbol{i k}}\left(\boldsymbol{t}_{\boldsymbol{i k}}\right) \boldsymbol{\alpha}^{\boldsymbol{T}}\right)}{\sum_{l=1}^{n} Y_{l k}\left(t_{i k}\right) \exp \left(\boldsymbol{Z}_{\boldsymbol{i k}}\left(\boldsymbol{t}_{\boldsymbol{i k - 1}}+\boldsymbol{g}_{\boldsymbol{i k}}\right) \boldsymbol{\alpha}^{\boldsymbol{T}}\right)}
$$

where $n$ is the total number of horses in all races, defined in section 3.2. The coefficient vector $\boldsymbol{\alpha}$ of explanatory covariates $\boldsymbol{Z}_{\boldsymbol{i} \boldsymbol{k}}(\boldsymbol{t})$ in equation (3) is evaluated using partial likelihood estimation (Prentice et al., 1981).

\subsection{Competitive-event forecasting model and estimation procedures}

A number of multi-stage combined statistical forecasting techniques have been introduced in recent years for forecasting competitive/categorical based events. For example, Edelman (2007) proposed a kernel method for predicting winning events, Florez-Lopez (2007) 
introduced a three-stage statistical model based on multinomial logit regression for rating insurers, Lessmann et al. (2009) introduced an SVM-based classification model for horserace prediction and Lessmann et. al. (2012) proposed a two-stage approach to horserace prediction that combined a set of strong and diverse statistical models with CL models.

We also adopt a two-stage approach when modelling the impact of the time elapsed since a horse's previous win on its winning probability in a given race. In particular, we employ predictions from a first stage survival analysis into a CL model.

The CL model enables us to account for the competition within a race whilst enabling the relationship between the winning probability and the independent variables to be discerned (this is not possible with non-parametric approaches). This is important, as we wish to determine the extent to which the DBW adds to the predictive ability of market prices. In fact, it has been shown that simpler binary classifiers, like CL, which facilitate interpretability, predict accurately and are viable alternatives to more sophisticated alternatives such as neural networks (Jones et al., 2015). Consequently, to achieve our objective, we employ the conditional logit (CL) model (e.g., Bolton \& Chapman, 1986) as a second stage in our modelling process. CL has been established as the benchmark model for predicting winning probabilities for horseraces since it directly models within-race competition between runners (i.e. ensures that the predicted winning probabilities for runners within a race sum to one). The CL horserace forecasting model predicts a vector of winning probabilities $\boldsymbol{p}_{\boldsymbol{i}}^{j}=\left(p_{1}^{j}\right.$, $\left.p_{2}^{j} \ldots, p_{n_{j}}^{j}\right)$ for race $j$ where $\boldsymbol{p}_{\boldsymbol{i}}^{j}$ represents the estimated probability of horse $i$ winning race $j$, with $n_{j}$ runners. Let $\boldsymbol{x}_{\boldsymbol{i}}^{\boldsymbol{j}}$ represent a single horse $i$ in race $j$ that is characterized by a number of independent variables, and $W_{i}^{j}$ be a binary win/lose indicator variable, defined as:

$$
W_{i}^{j}=\left\{\begin{array}{l}
1, \text { if } \boldsymbol{\beta} \cdot \boldsymbol{x}_{\boldsymbol{i}}^{j}+\varepsilon_{i}^{j}>\boldsymbol{\beta} \cdot \boldsymbol{x}_{\boldsymbol{l}}^{j}+\varepsilon_{l}^{j} \quad \forall i, l=1, \ldots n_{j}, i \neq l \\
0, \text { otherwise }
\end{array}\right.
$$

where $\boldsymbol{\beta}$ is a vector of coefficients which measure the relative contribution of the independent variables contained in the vector $\boldsymbol{x}_{\boldsymbol{i}}^{j}$, and the error term $\varepsilon_{i}^{j}$ represents unperceived information for horse $i$. If the errors are independent and distributed according to the double exponential distribution, the probability of horse $i$ winning race $j$ is given by the following CL function (McFadden, 1974):

$$
p_{i}^{j}=\frac{\exp \left(\boldsymbol{\beta} \cdot \boldsymbol{x}_{\boldsymbol{i}}^{j}\right)}{\sum_{i=1}^{n_{j}} \exp \left(\boldsymbol{\beta} \cdot \boldsymbol{x}_{\boldsymbol{i}}^{j}\right)}
$$


The model's coefficients, $\boldsymbol{\beta}$, are estimated by means of the maximum likelihood procedure (see Johnson et al., 2006).

We compare predictions of two CL models: the first incorporates a variable designed to capture information concerning winning probabilities derived solely from final bookmaker market prices. The second incorporates final bookmaker market prices together with the timerelated variable $P_{i}\left(t+\Delta t>T_{i} \geq t \mid T_{i} \geq t\right)$, specifically designed to capture the probability of a horse's next win occurring in a given race, based on the time since its previous winning performance. If predictions from the second model outperform those from the first, this will suggest that market prices do not fully incorporate information concerning the interval between a horse's winning performances. Our forecasting model is summarised by the twostage algorithm shown in Figure 3.2.

The two-stage algorithm depicted in Algorithm 3.2 employs SA in stage-1 to predict $P_{i}\left(t+\Delta t>T_{i} \geq t \mid T_{i} \geq t\right)$, in the manner discussed in Section 3.2. The explanatory variables in the SA are likely to interact with each other and most of them are time-dependent (i.e. they change in value in subsequent races (e.g., age). Consequently, in stage-1 we model: (i) the interaction of these variables with time duration since a horse's last winning performance and (ii) the impact of (i) on the chance of a horse winning its next race, given its last win was $x$ days ago. However, SA does not account for the competition between runners in a race. This competitive element is introduced by combining the SA and the CL models in a second stage. Here, the result derived from stage- 1 is used as an input variable for a CL model to estimate the winning probability $p_{i}^{j}$ for horse $i$ in race $j$. Consequently, the output of the stage-1, SA model can be interpreted as a 'condition' variable, i.e. an estimate of the degree to which the period since the horse's previous win is ideal in terms of maximising the horse's chance of winning the current race (given the horse's ability/physical condition etc.). In the CL model, we combine this condition variable with the horse's odds-implied-winprobability for the current race. If the probability estimates based on this two-stage approach are more accurate than those derived from a one-stage CL model with odds-implied-winprobability as the only independent variable, it implies that the time between a horse's winning performances is not fully discounted in the odds ${ }^{2}$.

\section{Algorithm 3.2: A two-stage algorithm to forecast horse win probability based on Survival analysis and the conditional logit model (SA/CL Model)}




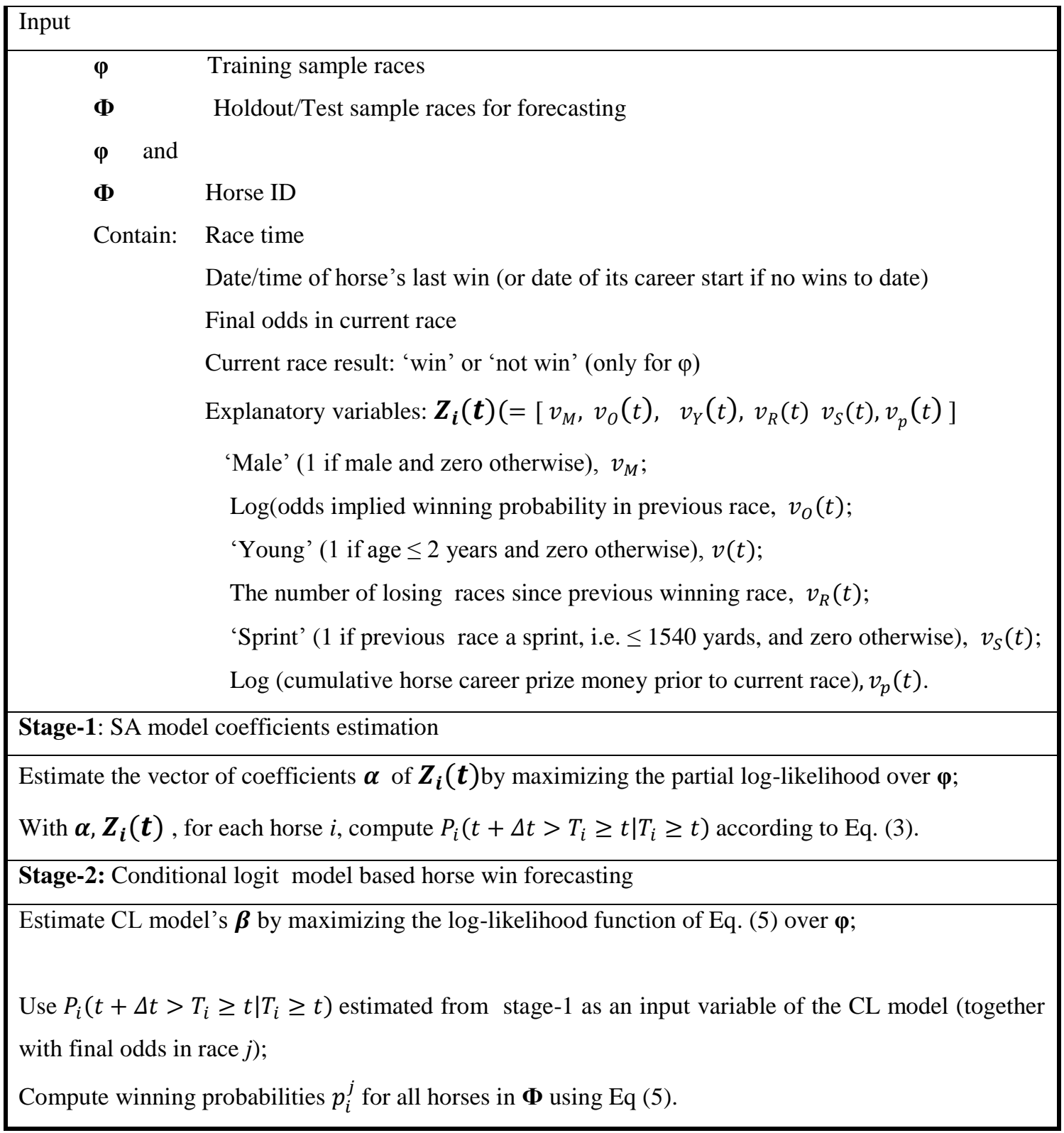

\subsection{Evaluation methodology}

\subsubsection{Testing hypotheses}

We test the 'Horse Physiological/Ability/Fitness Hypotheses' by examining the statistical significance of each of the explanatory variables in the SA model. These results show whether the factors we identify as relating to a horse's physiology/ability/fitness are linked to the chance of the horse winning its next race, based on the period since its last winning race.

In order to test the 'Duration Misperception Hypothesis', we explore whether bettors' probability forecasts, manifest in market prices, adequately account for a horse's DBW. To achieve this we proceed as follows: 
Step 1: the data for all horses in flat races run in 2005 are split into training $\phi\left(50 \%\right.$ : $1^{\text {st }}$ January to $2^{\text {nd }}$ July) and holdout $\Phi\left(50 \%: 3^{\text {rd }}\right.$ July to $5^{\text {th }}$ November $)$ datasets. We add to $\phi$ the complete past performance records of all the horses that ran in this period (some past performances dating back to January 1996). We use this enhanced training dataset to conduct the SA (see Eq. (2)), thus enabling us to estimate the coefficient $\boldsymbol{\alpha}$ for the covariate vector.

Step 2: In order to calculate $\hat{P}_{i}$, the estimated value of $P_{i}\left(t+\Delta t>T_{i} \geq t \mid T_{i} \geq t\right)$ for those horses that ran for the first time in 2005, we assign the average winning duration calculated from $\phi$. For those horses that ran in 2005 but had no wins up to the censor date, we assign the longest waiting durations derived from $\phi$.

Step 3: With assign values from step 2 and using the estimated coefficient from $\phi$, we calculate $\hat{P}_{i}$ for each horse that ran in 2005 using Eq. (3). We then estimate a CL model (using $\phi$ ), which included $\hat{P}_{i}$ and the log of the odds-implied winning probability (i.e. $\log$ $\left.\left(1 /\left[1+O_{i j}\right]\right)\right)$.

Step 4: We estimate (using $\phi$ ) a CL model incorporating a single explanatory variable, log $\left(1 /\left[1+O_{i j}\right]\right)$, for each horse. The log-likelihoods of this model and for the model specified in step 3 are compared, to examine whether market odds fully capture all the information contained in $\hat{P}_{i}$.

Step 5: It has been shown that probabilities estimated by maximum likelihood yield maximum in-sample return (on investments based on the basis of these estimated probabilities) to a $\log$ utility investor (Johnstone, 2011). However, we also need to demonstrate the economic significance of any differences in the accuracy of the predicted winning probabilities derived from the CL models developed in steps 3 and 4 for the holdout races $\Phi$. Specifically, we assess the economic significance of improvements in the predicted win probabilities derived from a model incorporating $\hat{P}_{i}$ and market odds, over that simply incorporating market odds. To achieve this we employ a Kelly wagering strategy ${ }^{3}$, which is designed to fully exploit differences between the win probability implied by a horse's odds and the model-predicted win probabilities (Kelly, 1956). This wagering strategy has been used in a number of betting market studies (e.g., Edelman, 2007; Johnson et al., 2006; Gu et al., 2003) and ensures that the asymptotic rate of growth for wealth is maximized, with zero probability of ruin, if arbitrarily small bets are permitted. Under this strategy, the fraction of current wealth bet on race $j$ is given by $f_{j}=\sum_{i=l}^{n_{j}} f_{j}(i)$, where $f_{j}(i)$ is the fraction of wealth 
bet on horse $i$ in race $j$, with $n_{j}$ runners. If horse $l$ with odds $O_{l j}$ wins race $j$, this will lead to current wealth increasing by a factor of:

$$
1-\sum_{i=l}^{n_{j}} f_{j}(i)+f_{j}(l)\left(O_{l j}+1\right)
$$

The Kelly strategy consists of choosing $f_{j}$ to maximize the expected $\log$ payoff, $F\left(f_{j}\right)$ where

$$
F\left(f_{j}\right)=\sum_{l=1}^{n_{j}} p_{i}^{j} \ln \left(1-\sum_{i=l}^{n_{j}} f_{j}(i)+f_{j}(l)\left(O_{l j}+1\right)\right)
$$

Consequently, the wagers most likely to increase wealth are more heavily weighted. In particular, when the expected return is greater (for the same winning probability) and the probability of winning is greater (for the same expected return) the bet size is larger. Consequently, a Kelly strategy identifies which races to bet on and how much to bet on each horse. We apply the Kelly strategy 'without' and 'with reinvestment': the former assumes that the maximum funds available are equal at the time of each bet (e.g. \$1), and the latter assumes that we start with an initial level of wealth $(\$ 1)$ and the total won/lost to date is added/subtracted in order to determine the maximum funds available at the time of each bet. In both cases, the Kelly formula determines the fraction of wealth to bet.

We perform two tests using the Kelly wagering strategy. First, we compare the profits resulting from the models developed at steps 3 and 4 . Second, to overcome the concern that the profit derived from the Kelly wagering strategies may be affected by the fortuitous selection of a particular set of test races or due to the order of races, we employ bootstrap methods. Specifically, we randomly sample, with replacement, from $\phi$ and $\Phi$ respectively, to produce a new bootstrapped training sample $\phi '$ and a new holdout sample $\Phi$ ', ensuring that $\phi$ ' $+\Phi^{\prime}$ involve the same number of races as in the original 2005 dataset, with $\phi$ 'and $\Phi$ ' each having an equal number of races. CL models incorporating (a) $\log \left(1 /\left[1+O_{i j}\right]\right)$ and (b) $\log \left(1 /\left[1+O_{i j}\right]\right)$ together with $\hat{P}_{i}$ were then estimated using the $\phi '$. The winning probabilities estimated by these CL models for the races in $\Phi$ ' are then used to inform Kelly wagering strategies. We repeat the above bootstrapping and Kelly wagering procedures 1000 times in order produce 1000 estimates of profit derived for the holdout races for CL models (a) and (b).

\subsubsection{Controlling for favorite-longshot bias}

It is widely documented that a favorite-longshot bias (FLB) exists in horseracing, whereby favourites are under-bet and longshots are over-bet (e.g., Bruce and Johnson, 2000). However, 
the consensus of these studies is that the bias is not sufficient to enable abnormal returns to be generated (e.g. Vaughan Williams and Paton, 1997; Law and Peel, 2002; Levitt, 2004; Snowberg and Wolfers, 2005). Previous literature, therefore, suggests that any abnormal returns we generate using predictions from a model incorporating $\widehat{\mathrm{P}}_{\mathrm{i}}$ and $1 /\left[1+\mathrm{O}_{\mathrm{ij}}\right]$ are unlikely to have arisen from simply exploiting the FLB. However, we develop a set of procedures to ensure that FLB is not contributing to these results. In particular, we first test for evidence of the FLB in the odds by examining the coefficient of $\log \left(1 /\left[1+\mathrm{O}_{\mathrm{ij}}\right]\right)$ in a $\mathrm{CL}$ with this as the sole independent variable. As reported in the results, we find that this coefficient is significantly greater than 1 , signalling that bettors do indeed under-bet favorites and over-bet longshots (Johnson and Bruce, 2001).

Using the log transformation of $1 /\left[1+O_{i j}\right]$ in the CL model helps to correct for this bias. However, to be confident that the transformation removes FLB in the holdout sample we use to evaluate the importance of the survival variable $\hat{P}_{i}$, we employ the methodology suggested by Ali (1977). In particular, we separate horses into seven categories based on their normalised odds-implied probability of winning. We then examine the ratio of the observed to the estimated number of winners in each category (based on predictions from CL models with (a) $\log \left(1 /\left[1+O_{i j}\right]\right)$ and (b) $\log \left(1 /\left[1+O_{i j}\right]\right)$ and $\hat{P}_{\mathrm{i}}$ as independent variables. If the observed/estimated winner ratio is significantly less/greater than 1 then it suggests that horses in this category are over/under bet (i.e. the predictions based on this model suggests that there should be more/less winners in this category than are observed).

To further reduce the possibility that any abnormal returns we generate using predictions from a CL model incorporating $\log \left(1 /\left[1+O_{i j}\right]\right)$ and $\hat{P}_{\mathrm{i}}$ have arisen from exploiting the FLB, we use the CL model incorporating $\log \left(1 /\left[1+O_{i j}\right]\right)$ as the sole independent variable to make predictions of winning probabilities for horses in the holdout races. We then employ a Kelly betting strategy based on these predicted probabilities. Clearly, if this strategy fails to make profits then any abnormal returns we generate from the CL model incorporating both $\log \left(1 /\left[1+O_{i j}\right]\right)$ and the survival variable, $\hat{P}_{i}$, are derived from the additional information contained in the survival variable.

\section{Results}

\subsection{Survival analysis estimation results}

We present the results of the SA in Table 4.1. All the model's explanatory variables are statistically significant at the 5\% level. These results support the central thesis of our 'Horse 
Physiological/Ability/Fitness Hypotheses'. In particular, the results suggest that the factors we identified relating to a horse's physiology/fitness (age, gender, distance of previous race) and ability (accumulated prize money, odds-implied probability in previous race, number of losing races since previous win) all impact the probability of a horse winning the current race, provided it has been a certain number of days since its previous winning race (as estimated using $\hat{P}_{i}$ ). In fact, all the independent variables are positively related to $\hat{P}_{i}$, suggesting that those horses which are male, younger, running in a sprint in their previous race and have proven ability (i.e. were expected to do well in their previous race and had higher accumulated prize money), are less likely to have long periods between winning races. These results confirm the views underlying our hypotheses that horses which are male, younger, which run in shorter distance races and have proven ability are more likely to recover quickly after exerting maximum effort (i.e. after a winning performance), thus reducing their DBW. Horses with more losing races since their last winning race are also likely to have a shorter period between winning races. If, as we discussed in section 2.1 , this variable is treated simply as an ability indicator (higher ability horses having a higher win/lose ratio) then this would, rather strangely, suggest that lower ability horses are more likely to have a shorter period between winning races. However, our equation already captures horse's ability via its accumulated prize money and whether it was expected to do well in its previous race (via its odds in that race). Consequently, the fact that the number of losing races since a previous win is positively related to $\hat{P}_{i}$ may simply indicate that horses gain racing fitness by running in races (better than they can on the training gallops). Consequently, our results suggest that horses of equal ability that have losing runs following a previous win are more likely to be racing fit. They are, therefore, likely to have a shorter period between winning races than those horses simply prepared on the training gallops.

The degree to which each of the independent variables influence the partial likelihood for estimating the Cox PHM is shown by the hazard ratios displayed in Table 4.1. For example, a one unit increase in the logarithm of accumulated prize money increases the horse's winning likelihood by $8.3 \%$ (Hazard Ratio $=1.083$ ). Our results, therefore, suggest that age and gender of the horse are the most influential variables in terms of their effect on the DBW.

Table 4.1: Survival analysis based on 2005 training dataset and horses' previous racing careers

\begin{tabular}{llll}
\hline Covariates & Coefficient & S.D. & Hazard Ratio* \\
\hline $\begin{array}{l}\text { Log }(1 /(1+\text { start odds in } \\
\text { prev. race) }\end{array}$ & $0.0824^{*}$ & $(0.0124)$ & 1.0860
\end{tabular}


Log (Cum prize money

won to race date $(\mathfrak{f}))$

Age $(\leq$ two years $=1)$

Gender $($ male $=1)$

Race dist. ( sprint $=1$ )

Number of losing races between winning races ${ }^{4}$

Log-Likelihood
$0.0797 *$

$0.8361^{*}$

$0.3308 *$

$0.0225^{*}$

$0.0209^{*}$

$-53885.7$
1.0830

2.3070

1.3920

1.0230

1.0210

${ }^{*}$ Hazard Ratio=exp(coefficient); * Significant at 5\%

\subsection{Conditional logit estimation results}

We estimate three conditional logit models. The first two models (M1 and M2) each include one explanatory variable, $\log \left(1 /\left[1+O_{i j}\right]\right)$ and $\hat{P}_{i}$ (derived from Eq. (3)), respectively. The third model (M3) incorporates both $\log \left(1 /\left[1+O_{i j}\right]\right)$ and $\hat{P}_{i}$. These models are all estimated using $\varphi$. We present the estimated coefficients, together with their associated standard deviations, in Table 4.2. In line with previous studies, the results of estimating M1 suggest that a horse's odds implied probability is positively and significantly related to its probability of winning (e.g. Bruce and Johnson 2000). We reject the null hypothesis that $\hat{P}_{i}$ has no explanatory power, as the coefficient of $\hat{P}_{i}$ in M2 is significantly different to zero at the 5\% level. In addition, the coefficients of both $\log \left(1 /\left[1+O_{i j}\right]\right)$ and $\hat{P}_{i}$ are significantly different to zero at the $5 \%$ level in M3, suggesting that the information content of $\hat{P}_{i}$ is not fully captured in market prices. The view that more information is captured by M3 (log-likelihood=4670.7) than by M1 (log-likelihood=-4823.8) is confirmed by a nested log likelihood ratio test, the chi-square test statistic (-306.26) being significant at the 5\% level.

Table 4.2: Results from estimating conditional logit models using the training dataset

\begin{tabular}{llll}
\hline Covariates & Model 1 & Model 2 & Model 3 \\
$\log (1 /[1+$ Odds $]$ & $1.1691^{*}$ & -- & $1.0914^{*}$ \\
\multicolumn{1}{c}{$\hat{P}_{i}$} & $(0.0314)$ & --- & $(0.0316)$ \\
& --- & $0.4055^{*}$ & $0.3093^{*}$ \\
& -- & $(0.0157)$ & $(0.0174)$ \\
\hline Log-Likelihood & -4823.80 & & -4670.67 \\
$\chi^{2}$ statistics & & -5418.30 & $-306.26^{*}$ \\
& & M1 vs. M3 & $-1495.25^{*}$
\end{tabular}

Notes: Standard errors are reported in parentheses. * Significant at the 5 percent level.

Chi-square statistics are reported with degrees of freedom equal to the number of restrictions being tested. Critical value at the $5 \%$ significance levels for $\chi^{2}(1)$ is 3.84 .

\subsection{Economic significance of the results}


The economic importance of the duration misperception of the betting public (indicated by the fact that $\hat{P}_{i}$ is not fully discounted in odds) can only be discerned by exploring the extent to which it is possible to earn abnormal returns using this information. Consequently, we compare the performance of a Kelly wagering strategy with reinvestment, using the estimated winning probabilities for horses running in races in the holdout sample $\Phi$ (2258 races in 2005), predicted by models (a) M1 and (b) M3, both developed using the training data set $\phi$. The cumulative profits arising from these two wagering strategies, assuming that one starts with a bank of $\$ 1$ are shown in Figure 4.1.

Figure 4.1: Cumulative profit from a Kelly wagering strategy with reinvestment for the holdout races (initial bank \$1), based on win probabilities predicted by (a) a CL model with $\log \left(1 /\left[1+O_{i j}\right]\right)$ only (M1), (b) a CL model with $\log \left(1 /\left[1+O_{i j}\right]\right)$ and six independent variables, namely age, gender, distance of previous race, accumulated prize money, odds-implied probability in previous race and number of losing races since previous win (M4); and (c) a CL model with $\log \left(1 /\left[1+O_{i j}\right]\right)$ and $\widehat{P}_{i}$ (modelled using the six independent variables in M4 but employed using survival analysis) (M3).

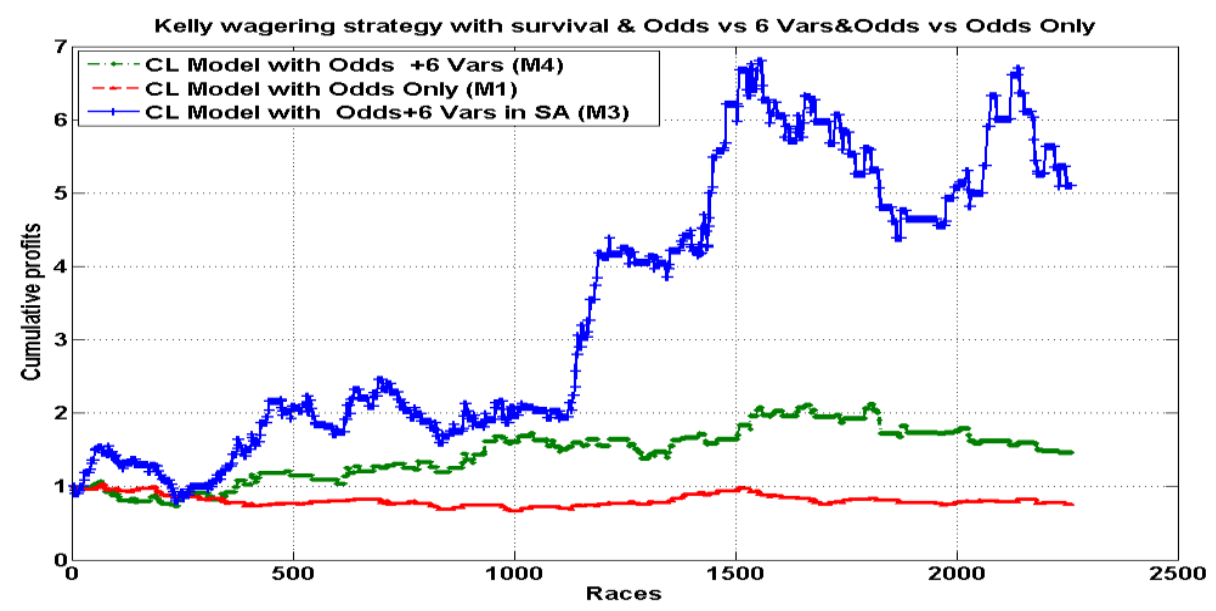

It is clear from the results displayed in Figure 4.1, that a betting strategy simply based on market odds is very unlikely to be profitable. In fact, starting with a bank of $\$ 1$, bets based on predictions from M1 in the holdout sample $\Phi$ lead to the bank reducing to $\$ 0.759$, a loss of $24.1 \%$. However, bets based on M3 result in the bank increasing to $\$ 5.094$, a gain of $409.4 \%$. These results clearly suggest that $\hat{P}_{i}$ adds considerably to the information related to a horse's chances of winning contained in market odds.

We conduct tests to ensure that the improvement of M3 over M1 arises because bettors do not account for DBW, rather than simply because other variables related to a horse's chance of winning were included in M3. In particular, we examine whether the 
explanatory variables we use to model the chance of a horse winning given the time since its last win, might themselves (irrespective of their ability to model time between winning performances) be responsible for the improved performance of M3 over M1. Consequently, we develop a CL model (M4). This incorporates the log of the odds implied probability (log $\left(1 /\left[1+O_{i j}\right]\right)$ together with the three factors related to a horse's physiology/fitness (age, gender, distance of previous race) and the three factors related to a horse's ability (accumulated prize money, odds-implied probability in previous race, number of losing races since previous win) which we use in SA. Our aim is to examine the degree to which M3 out-performs M4. Any additional profit achieved by employing a Kelly betting strategy based on the predictions of M3 (cf. the predictions of M4) in the holdout races, would represent the economic significance of the duration misperception suffered by bettors which was captured by our survival analysis approach.

Figure 4.1 shows that the predictions of M3 significantly outperform those from M4 and M1. These results demonstrate that the full information value of the three physiology/fitness variables and the three ability variables are only fully unlocked by incorporating their effect on DBW. In other words, a CL model alone cannot extract the full information value of these variables in relation to DBW.

Finally, to confirm that our results do not arise from fortuitous selection of a particular set of test races, or due to the order of races in $\Phi$, we conduct the bootstrap simulation outlined in section 3.4. We show the results of this simulation, across 1000 simulations of 2258 randomly selected holdout races, in Figure 4.2

Figure 4.2 Results of 1000 simulations across bootstrapped holdout samples: Comparing the average cumulative profit arising from a Kelly wagering strategy with reinvestment based on win probabilities predicted by CL models with (a) $\log \left(1 /\left[1+O_{i j}\right]\right)(\mathrm{M} 1)$ and $(b) \log \left(1 /\left[1+O_{i j}\right]\right)$ and $\widehat{\mathrm{P}}_{\mathrm{i}}$ as independent variables (M3). 


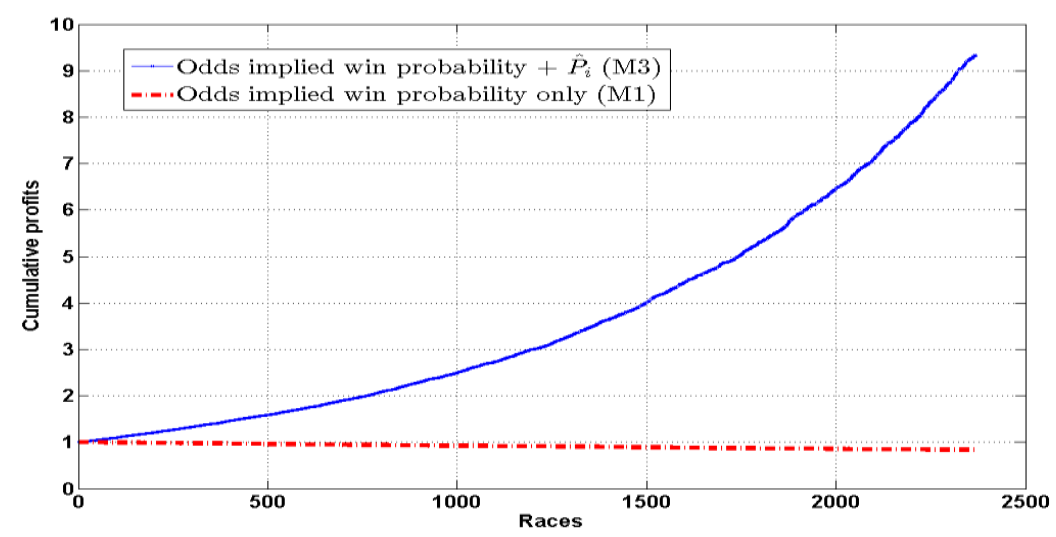

The results of the bootstrap simulation clearly suggest that information concerning $\hat{P}_{i}$ is not fully discounted in market odds, and that it is possible to make abnormal returns via a betting strategy that makes appropriate use of this information. However, a loss is incurred if we simply rely on predictions based on odds implied probabilities. In particular, a Kelly strategy over the holdout races, based on predictions from M3, would have resulted in an average increase in wealth of $932.5 \%$ with reinvestment of winnings (equivalent to $16.27 \%$ return without reinvestment of winnings). However, a Kelly strategy over the holdout races, based on predictions from M1, would have resulted in a decrease in wealth of $16.35 \%$ (equivalent to a decrease of $5.86 \%$ without reinvestment). These results confirm our main 'Duration Misperception Hypothesis,' that bettors do not adequately discount the information contained in DBW.

\subsubsection{Confirming the results do not arise from the favorite-longshot bias}

As indicated in section 3.4.2, we conduct a series of tests to ensure that our results hold after controlling for the FLB. This is important because we find that favorites are under-bet and longshots are over-bet in our sample of races. In particular, for the results displayed in table 4.2, the coefficient of $\log (1 /[1+\mathrm{Oij}])$ in $\mathrm{M} 1$ is significantly greater than $1(\mathrm{t}=5.39, \mathrm{p}<.01)$.

To examine if the log transformation of odds-implied probability eliminates this bias we examine the ratio of the observed to the estimated number of winners in each of seven categories of odds, based on predictions from M1 and M3. The results are displayed in tables 4.3 and 4.4. There are no significant differences (at the 5\% level) in the estimated and actual number of winners in any of the seven categories of odds-implied probability in either table. The results presented in table 4.3 suggest that the log transformation of odds does indeed remove any FLB and those presented in Table 4.4 indicate that there is no FLB in the predictions from M3. 


\begin{tabular}{|c|c|c|c|c|c|c|c|c|c|}
\hline \multirow{2}{*}{$\begin{array}{c}\text { Odds- } \\
\text { implied } \\
\text { prob. }\end{array}$} & \multirow{2}{*}{$\begin{array}{l}\text { Number } \\
\text { Runners }\end{array}$} & \multicolumn{2}{|c|}{ Number Winners } & \multicolumn{2}{|c|}{$\begin{array}{l}\text { Mean win } \\
\text { probability }\end{array}$} & \multirow{2}{*}{$\begin{array}{c}\text { Obs/Est } \\
\text { prob. } \\
\text { Ratio }^{3}\end{array}$} & \multirow{2}{*}{$\begin{array}{c}\text { Std } \\
\text { Error }^{4}\end{array}$} & \multirow{2}{*}{$\begin{array}{c}\mathrm{z}- \\
\text { score }^{5}\end{array}$} & \multirow{2}{*}{ p-value ${ }^{5}$} \\
\hline & & Estimated $^{1}$ & Observed & Estimated $^{1}$ & Observed $^{2}$ & & & & \\
\hline $\begin{array}{l}0.00- \\
0.05 \\
\end{array}$ & 10696 & 235.76 & 227 & 0.0220 & 0.0212 & 0.9628 & 0.0014 & -0.5876 & 0.5568 \\
\hline $\begin{array}{l}0.05- \\
0.10 \\
\end{array}$ & 7451 & 504.68 & 543 & 0.0677 & 0.0729 & 1.0759 & 0.0030 & 1.7079 & 0.0877 \\
\hline $\begin{array}{l}0.10- \\
0.15\end{array}$ & 3518 & 434.23 & 422 & 0.1234 & 0.1199 & 0.9718 & 0.0055 & -0.6347 & 0.5256 \\
\hline $\begin{array}{l}0.15- \\
0.20\end{array}$ & 1989 & 363.26 & 377 & 0.1826 & 0.1895 & 1.0378 & 0.0088 & 0.7861 & 0.4318 \\
\hline $\begin{array}{l}0.20- \\
0.25 \\
\end{array}$ & 970 & 230.86 & 231 & 0.2380 & 0.2381 & 1.0006 & 0.0137 & 0.0104 & 0.9917 \\
\hline $\begin{array}{l}0.25- \\
0.30\end{array}$ & 510 & 152.3 & 143 & 0.2986 & 0.2804 & 0.9389 & 0.0199 & -0.9171 & 0.3591 \\
\hline 0.3-1.00 & 755 & 336.91 & 315 & 0.4462 & 0.4172 & 0.9349 & 0.0179 & -1.6168 & 0.1059 \\
\hline Notes: & \multicolumn{9}{|c|}{$\begin{array}{l}\text { 1. The estimated win probabilities are based on predictions from a CL model with one predictor variable (log } \\
\left.\left(1 /\left[1+O_{i j}\right]\right)\right) \text {. The estimated number of winners in each category is the sum of the estimated win probabilities of } \\
\text { the horses in this category. } \\
\text { 2. The 'observed mean win probability' is the number of winners/total number of runners in this category. } \\
\text { 3. Obs/Est ratio is the ratio of the observed and estimated win probabilities. Due to rounding of the observed and } \\
\text { estimated win probabilities, the ratio values do not always concur with a simple division of the numbers given in } \\
\text { the table. } \\
\text { 4. The std. error of the observed probability is given by sqrt(observed probability* (1- observed } \\
\text { probability))/number of runners in the category (Ali, 1977). } \\
\text { 5. The z-score and p-values relate to whether the observed probability - estimated probability is significantly } \\
\text { different to } 0 \text { (Ali, 1977). }\end{array}$} \\
\hline
\end{tabular}

\begin{tabular}{|c|c|c|c|c|c|c|c|c|c|}
\hline \multirow{2}{*}{$\begin{array}{c}\text { Odds- } \\
\text { implied } \\
\text { prob. }\end{array}$} & \multirow{2}{*}{$\begin{array}{l}\text { Number } \\
\text { Runners }\end{array}$} & \multicolumn{2}{|c|}{ Number Winners } & \multicolumn{2}{|c|}{$\begin{array}{l}\text { Mean win } \\
\text { probability }\end{array}$} & \multirow{2}{*}{$\begin{array}{c}\text { Obs/Est } \\
\text { prob. } \\
\text { Ratio }^{3}\end{array}$} & \multirow{2}{*}{$\begin{array}{c}\text { Std } \\
\text { Error }^{4}\end{array}$} & \multirow{2}{*}{$\begin{array}{c}\text { z- } \\
\text { score }^{5}\end{array}$} & \multirow{2}{*}{ p-value } \\
\hline & & Estimated $^{1}$ & Observed & Estimated $^{1}$ & Observed $^{2}$ & & & & \\
\hline $\begin{array}{l}0.00- \\
0.05\end{array}$ & 10696 & 246.32 & 227 & 0.0230 & 0.0212 & 0.9215 & 0.0014 & -1.2963 & 0.1949 \\
\hline $\begin{array}{l}0.05- \\
0.10\end{array}$ & 7451 & 508.91 & 543 & 0.0683 & 0.0729 & 1.0670 & 0.0030 & 1.5194 & 0.1287 \\
\hline $\begin{array}{l}0.10- \\
0.15\end{array}$ & 3518 & 427.90 & 422 & 0.1216 & 0.1199 & 0.9862 & 0.0055 & -0.3063 & 0.7594 \\
\hline $\begin{array}{l}0.15- \\
0.20\end{array}$ & 1989 & 354.47 & 377 & 0.1782 & 0.1895 & 1.0635 & 0.0088 & 1.2891 & 0.1974 \\
\hline $\begin{array}{l}0.20- \\
0.25\end{array}$ & 970 & 232.24 & 231 & 0.2394 & 0.2381 & 0.9946 & 0.0137 & -0.0938 & 0.9253 \\
\hline $\begin{array}{l}0.25- \\
0.30\end{array}$ & 510 & 153.34 & 143 & 0.3007 & 0.2804 & 0.9325 & 0.0199 & -1.0196 & 0.3079 \\
\hline $0.3-1.00$ & 755 & 334.81 & 315 & 0.4435 & 0.4172 & 0.9408 & 0.0179 & -1.4624 & 0.1436 \\
\hline Notes: & \multicolumn{9}{|c|}{$\begin{array}{l}\text { 1. The estimated win probabilities are based on predictions from a CL model with two predictor variable (log } \\
\left.\left(1 /\left[1+O_{i j}\right]\right) \text { and the survival variable } \widehat{P}_{i}\right) \text {. The estimated number of winners in each category is the sum of the } \\
\text { estimated win probabilities of the horses in this category. } \\
\text { 2. The 'observed mean win probability' is the number of winners/total number of runners in this category. } \\
\text { 3. Obs/Est ratio is the ratio of the observed and estimated win probabilities. Due to rounding of the observed and } \\
\text { estimated win probabilities, the ratio values do not always concur with a simple division of the numbers given in } \\
\text { the table. } \\
\text { 4. The std. error of the observed probability is given by sqrt(observed probability* (1- observed } \\
\text { probability)/number of runners in the category (Ali, 1977). } \\
\text { 5. The z-score and p-values relate to whether the observed probability - estimated probability is significantly } \\
\text { different to } 0 \text { (Ali, 1977). }\end{array}$} \\
\hline
\end{tabular}


Given these results, we feel that there may be limited interaction between FLB and the duration misperception. To verify this expectation, we develop a new CL model incorporating three variables, $\log (1 /[1+\mathrm{Oij}])$, our SA variable $\hat{P}_{i}$ and the interaction variable $\log (1 /[1+\mathrm{Oij}]) \times \hat{P}_{i}$. If duration misperception is more pronounced for favorites or longshots then this term should be significant. However, estimating this model based on the training dataset we find that the coefficient of this interaction term is 0.0128 , with a p-value of 0.2938. This result suggests that there is no significant interaction between FLB and duration misperception.

Furthermore, as shown in section 4.3, Kelly wagering strategies, based on predictions from M3 (a model incorporating $\log (1 /[1+\mathrm{Oij}])$ and the survival variable, $\left.\hat{P}_{i}\right)$ and M1 (a CL model only incorporating $\log (1 /[1+\mathrm{Oij}])$ for the holdout races, result in a bank of $\$ 1$ increasing to $\$ 5.094$ (a gain of $409.4 \%$ ) and reducing to $\$ 0.759$ (a loss of $24.1 \%$ ), respectively. These results clearly suggest that $\hat{P}_{i}$ adds considerably to the information related to a horse's chances of winning contained in market odds and that it is not possible to secure abnormal returns by exploiting the FLB.

Taken together, the results outlined in this section provide strong evidence that the significant profits we derive from predictions based on a CL model incorporating log $(1 /[1+\mathrm{Oij}])$ and the survival variable $\hat{P}_{i}$, are not derived from FLB.

\subsection{Duration misperception}

Our conclusion that odds do not fully account for DBW is important, since previous research has shown betting markets to comply with the semi-strong EMH. In particular, previous studies have found that market odds provide a good guide to winning probabilities across different countries and for a variety of events (e.g., Sauer, 1998; Vaughan Williams, 1999; Snowberg \& Wolfers, 2010). In fact, as indicated above, even though odds often under/over-estimate the chances of favorites/longshots, it has generally been concluded that this knowledge does not permit profitable exploitation (e.g., Levitt, 2004; Snowberg \& Wolfers, 2010).

Our results demonstrate that horserace bettors are not proficient in interpreting time related information. In fact, we take an apparently intuitive concept, the time since a horse's last win and demonstrate that this information is not fully discounted in market odds. In particular, we show that by modelling this information appropriately, using SA, significant profits can be achieved without the need for combining this with other complex variables (e.g. 
related to the horse's or jockey's ability). Our results suggest therefore, that the limits of bettors' forecasting ability may not simply be challenged by the complexity associated with variable combination, but also by the complexity associated with modelling individual timerelated variables appropriately.

\section{Conclusion}

We identify duration misperception linked to fundamental variables as an important source of bias in speculative prices. In particular, we demonstrate that market odds do not even fully discount time-based information which is well known to affect winning probabilities and that the cognitive bias leads to an inefficient market. We show how duration can be modelled using SA and we believe that this is the first time that SA has been applied to study pricing efficiency in a speculative market. Specifically, we develop an interval model, adapted from Prentice et al.'s (1981) model for discrete events, which is designed to predict the conditional event probability in the period since the last event occurred (i.e.. since a horse's last win). This model combines SA with the CL model; creating a two-stage algorithm which can accurately predict winning probabilities in horseraces, employing individual horses' characteristics related to the time between winning performances and accounting for withinrace competition. Our results show that this modelling approach produces effective probability forecasts. When employed in conjunction with an optimised betting strategy, these produce significant abnormal profits.

Our results demonstrate that even decision makers whose probability forecasts are generally well calibrated (i.e. bettors), particularly with respect to individual pieces of information relevant to the event being forecast, do not appropriately model information concerning the time since a previous event (i.e. a horse's last win). In particular, it appears that even in markets which offer significant rewards to accurate judgements, participants fail to use duration-based information appropriately. The finding is in line with results from the psychology and decision science literature that suggests people are remarkably poor at interpreting duration-based variables (e.g, Sterman 1989, 2000; Fu \& Gonzalez 2006, Moxnes, 1998; Cronin \&Gonzalez, 2007; Ossimitz, 2002; Sweeney \& Sterman, 2000). This suggests that, even in markets which are generally regarded as efficient, it is important that appropriate models are employed to support agent's decision making. We demonstrate that this is not simply important for combining a range of complex variables (as previous studies suggest) but also for appropriately handling information which decision makers appear less 
well adapted to interpret (i.e. that with a duration element). We estimate that duration misperception in horserace markets alone reduces returns by $22.13 \%$ (i.e. comparing the returns to a Kelly betting strategy without reinvestment for M3 and M1 (16.27\% and -5.86\%). Clearly, if, as seems likely, investors in broader financial markets and decision makers in other domains (e.g. in project management) suffer similar effects, the impact of duration misperception on the global economy is likely to be significant.

The methodology employed here could be adopted in a variety of research studies in the field of Operational Research. In particular, it would be useful to extend the ideas to areas for which CL models were originally designed, specifically in the fields of marketing and public choice, where it is important to account for both time-to-event and competition (e.g., choices among multiple products/services). For example, the adoption of our two-stage SACL based modelling approach may enable significantly better predictions of companies/consumers' choices from a limited range of available products/services. In particular, these models would allow more effective use of the time since a consumer's or company's last purchase/selection. This could offer significant benefits to both commercial organisations and Governments. For example, when assessing the impact on credit availability of the length of a firm's relationship with its bank (Ongena \& Smith, 2001) our model can account for not only the duration of a firm's relationship with its bank but also competition among banks. Our two-stage approach could also account for the competition among franchisor firms when assessing the survival of new franchisors (Shane \& Foo, 1999). It could also be employed to determine the inter-temporal price discrimination of repeated purchases (Chen et al., 2015) and repeated buyer prediction (Baesens et al., 2002) whilst accounting for the choices among available products. Furthermore, the two-stage approach we introduce could be used to assess the time to default of those holding personal loans whilst accounting for their choices between available loans (Stepanov \& Thomas, 2002).

There are also implications for fields such as political science, economics and finance, where SA has been used to analyse the interval between or before various events (see Kiefer, 1990 for a literature review) but where competition has not been taken into account,. For example, standard SA has been used to predict mutual funds' hazard rates of closure (Lunde et al., 1999). However, funds also need to compete in the market place and thus there is a competitive element that cannot be captured by SA alone. The application of our two-stage SA-CL approach would enable this element to be accounted for and should, therefore, provide more accurate predictions of the probability of closure. Similarly, our two-stage approach can be used to extend previous studies in assessing political election outcomes 
(Box-Steffensmeier and Jones, 1998; Bennett, 1999). The approach would not only account for the result and timing of a candidate's last election but also the competition with other candidates. Our SA-CL approach could also help to resolve a range of economics problems, such as the causes of variation in the length of time individuals remain unemployed (Meyer, 1990), the effect of wages on teacher turnover (Dolton and Van der Klaauw, 1995) and factors influencing the timing of females' transitions in the labour market (Bloemen and Kalwij, 2001). Previous studies exploring these issues have only adopted SA for evaluating the time-to-event effect. However, our approach would also enable researchers to account for competition for positions among unemployed individuals, teachers and female workers, respectively. The methodology developed here could, therefore, offer significant benefits to commercial organisations, governments and society.

\section{Endnotes}

1. The season for flat races run on turf usually extends from mid-March to early November. We adjusted our data to accommodate those horses that only ran on turf, so that the period between early November and mid-March (approx. 140 days) was not counted for determining the period between winning. In fact, because this represented an enforced layoff we took the decision to count this period as 30 days (which is often regarded as the ideal period between a horse's runs). Consequently, consider a horse that only ran on turf and had its last race, say, on October 25th in year $t$ and ran again on March 30th in year $t+1$. For this horse, the gap between runs was treated as 30 days plus the period between October 25th and the end of the flat season in year $t$, plus the period between the start of season $t+1$ and March 30th. Some horses also run on the flat outside of the period mid-March to early November on 'all weather' tracks (artificial surfaces). For horses that ran on both surfaces during their career, there was no need to adjust the observed periods between winning performances.

2. A CL model with two independent variables is not always better than the CL model with one independent variable. For example, a CL model with odds plus random noise as an independent variable will not produce more accurate probabilities than a CL model with odds only. The predictions are only improved when the additional variable incorporates additional information.

3. Our research purpose is to assess whether DBW is fully discounted by the betting public, rather than to produce the best possible forecasting model. Consequently, a Kelly wagering 
strategy with a betting simulation is more appropriate than methods that simply assess the accuracy of a prediction model (e.g. ROC/GINI).

4. A Pearson correlation test between the number of losing races between winning races $\left(v_{R}(t)\right)$ and time $\mathrm{t}\left(\mathrm{t}>\mathrm{v}_{\mathrm{R}}(\mathrm{t})\right)$ was performed: correlation coefficient $=0.1081$ indicating that these two variables are not strongly correlated.

\section{References:}

Ali, M.M. (1977). Probability and utility estimates of racetrack bettors. Journal of Political Economy, 83, 803-815.

Andersen, P. K. \& Gill, R. D. (1982). Cox's regression model for counting processes: A large sample study. The Annals of Statistics, Vol. 10, No. 4, 1100-1120.

Baesens,B., Viaene, S., Van den Poel, D., Vanthienen, J. \& Dedene, G. (2002) Bayesian neural network learning for repeat purchase modelling in direct marketing. European Journal of Operational Research. 138 (1), 191-211.

Bennett, D. (1999) Parametric models, duration dependence, and time-varying data revisited, American Journal of Political Science, 43, 256-270.

Bolton, R.N. \& Chapman, R.G. (1986). Searching for positive returns at the track: A multinomial logitmodel for handicapping horse races. Management Science, 32(8), 10401060.

Box-Steffensmeier, J. \& Jones, B. (1998). Time is of the essence: Event history models in political science, American Journal of Political Science, 41, 1414-1461.

Box-Steffensmeier, J. and Zorn, C. (2002). Duration models for repeated events. Journal of Politics, 64, 1069-1094.

Box-Steffensmeier, J. \& De Boef, S. (2006) Repeated events survival models: The conditional frailty model. Statistics in Medicine 25.20, 3518-3533.

Bloemen, H., \& Kalwij, A. (2001). Female labor market transitions and the timing of births: a simultaneous analysis of the effects of schooling. Labour Economics, 8, 593-620.

Bruce, A.C. \& Johnson, J.E.V. (2000). Investigating the roots of the favourite longshot bias: An analysis of decision making by supply- and demand-side agents in parallel betting markets. Journal of Behavioural Decision Making, Vol. 13, 413-430.

Canfield, B.R., Fauman, B.C. \& Ziemba, W.T. (1987). Efficient market adjustment of odds prices to reflect track biases. Management Science, Vol. 33, 1428-1439.

Ceaser, J. W., \& Busch, A. (Eds.). (1997). Losing to win: the 1996 elections and American Politics. Rowman \& Littlefield. 
Chen,Z., Liang, X.\& Xei, L. (2015), Inter-temporal price discrimination and satiety-driven repeat purchases. European Journal of Operational Research, Available online 3 November 2015 .

Clark, B. C., Manini, T. M., Doldo, N. A., \& Ploutz-Snyder, L. L. (2003). Gender differences in skeletal muscle fatigability are related to contraction type and emg spectral compression. Journal of Applied Physiology, 94(6), 2263-2272.

Cook R.J, Ng, E.T.M, Mukherjee, J. \& Vaughan, D. (1999). Two-state mixed renewal processes for chronic disease. Statistics in Medicine, 18(2), 175 -188.

Cox, D. (1972). Regression models and life tables. Journal of the Royal Statistical Society, B34, 187-220.

Crafts, N.F.R. (1985). Some evidence of insider knowledge in horse race betting in Britain. Economica, Vol. 52, 295-304.

Cronin, M.A., \& Gonzalez, C. (2007). Understanding the building blocks of dynamic systems. System Dynamics Review, 23, 1-17.

Dedrick, M.E. \& Clarkson, P.M. (1990). The effects of eccentric exercise on motor performance in young and older women. European Journal of Applied Physiology and Occupational Physiology, 60(3),183-186.

Dolton, P. \& Van der Klaauw, W. (1995). Leaving teaching in the UK: A duration analysis. The Economic Journal, 105, 431-444.

Edelman, D. (2007). Adapting support vector machine methods for horserace odds prediction. Annals of Operations Research 151 (1), 325-336.

Evans, D.L. (2007). Welfare of the racehorse during exercise training and racing, in the welfare of horses, ed. N. Waran, 181-201, Dordecht: Kluwer Academic Publishers.

Fama, E. F. (1970). Efficient capital markets: A review of theory and empirical work. The Journal of Finance, 25(2), 383-417.

Fama, E. F. (1991). Efficient capital markets: II. The Journal of Finance, 46(5), 1575-1617.

Fildes, R., Goodwin, P., Lawrence, M. \& Nikolopoulos, K. (2008). Effective forecasting and judgmental adjustments: An empirical evaluation and strategies for improvement in supplychain planning. International Journal of Forecasting. 25(1), 3-23.

Flores, R., Forrest, D., \& Tena, J.D. (2012), Decision taking under pressure: Evidence on football manager dismissals in Argentina and their consequences. European Journal of Operational Research, 222, pp. 653-662. 
Florez-Lopez, R. (2007): Modelling of insurers' rating determinants: An application of machine learning techniques and statistical models. European Journal of Operational Research, 183(3), pp. 1488-1512.

Frederickson, B. L. \& D. Kahneman (1993). Duration neglect in retrospective evaluations of affective episodes. Journal of Personality and Social Psychology, 65 (1): 45-55.

Fu., W.T., \& Gonzalez, C. (2006). Learning in Dynamic Decision-Making: Information Utilization and Future Planning. Pittsburgh, PA: Carnegie Mellon University, Department of Social and Decision Sciences.

Fulco CS, Rock PB, Muza SA, Lammi E, Cymerman A, Butterfield G, Moore, LG, Braun B, $\&$ Lewis SF (1999). Slower fatigue and faster recovery of the adductor pollicis muscle in women matched for strength with men. Acta Physiol Scand., 167(3): 233-239.

Goodwin, P. (2005). Providing support for decisions based on time series information under conditions for asymmetric loss. European Journal of Operational Research. 163(2), 388-402. Goodwin, P., Önkal, D., \& Thomson, M. (2010). Do forecasts expressed as prediction intervals improve production planning decisions? European Journal of Operational Research, 205(1):195-201.

Gu, M. G., Huang, C. \& Benter, W. (2003). Multinomial probit models for competitive horse racing. Paper presented at the Chinese University of Hong Kong, Hong Kong.

Hunter SK, Schletty JM, Schlachter KM, Griffith EE, Polichnowski AJ \& Ng AV (2006). Active hyperemia and vascular conductance differ between men and women for an isometric fatiguing contraction. Journal of Applied Physiology, 101, 140-150.

Hwang, J.H., \& Kim, M.-S (2015) Misunderstanding of the binomial distribution, market inefficiency, and learning behavior: Evidence from an exotic sports betting market. European Journal of Operational Research, 243 (1), pp. 333-344.

Jensen, M.C., (1978). Some anomalous evidence regarding market efficiency. The Journal of Financial Economics, 6:95-101.

Johnson, J.E.V., Jones, O. \& Tang, L. (2006). Exploring decision makers' use of price information in a speculative market. Management Science, 52(6), 897-908.

Johnson, J.E.V. and Bruce, A. C. (2001). Calibration of subjective probability judgments in a naturalistic setting. Organizational Behavior and Human Decision Processes, 85, 265-290

Johnstone, D. J. (2011). Economic interpretation of probabilities estimated by maximum likelihood or score. Management Science, 57 (2), 308-314. 
Jones, S., Johnstone, D., \& Wilson, R. (2015). An empirical evaluation of the performance of binary classifiers in the prediction of credit ratings changes. Journal of Banking and Finance, $56,72-85$.

Kamakura, W., Kossar, B., \& Wedel, M. (2004). Identifying innovations for the cross-selling of new products. Management Science, 50, 1120-1133.

Kiefer, N. (1990). Economic duration data and hazard functions. Journal of Economic Literature, 26, 646-679.

Kellmann, M., ed. (2002). Enhancing recovery: Preventing underperformance in athletes. Human Kinetics.

Kelly, J. L. (1956). A new interpretation of information rate. The Bell System Tech. Journal, 35, 917-926.

Klein, J.P. \& Moeschberger, M.L. (2003). SA: Techniques for censored and truncated data. Springer Verlag.

Lane, W.R., Looney, S.W. \& Wansley, J.W. (1986). An application of the Cox Proportional Hazards Model to bank failure. Journal of Banking and Finance, Vol. 10-4, 511-531.

Law, D. \& Peel, D.A., (2002). Insider trading, herding behaviour and market plungers in the British horse-race betting market. Economica, Vol. 69, 327-338.

Lessmann, S. Sung, M.-C. \& Johnson, J.E.V. (2009), Identifying winners of competitive events: A SVM-based classification model for horserace prediction. European Journal of Operational Research, 196(2), pp. 569-577.

Lessmann, S., Sung, M., \& Johnson, J.E.V. (2010). Alternative methods of predicting competitive events: an application in horserace betting markets. International Journal of Forecasting, 26(3), 518-536.

Lessmann, M-C. Sung, J.E.V. \& Johnson, T. Ma (2012). A new methodology for generating and combining statistical forecasting models to enhance competitive event prediction. European Journal of Operational Research, 218, 163-174.

Levitt, S.D., (2004). Why are gambling markets organised so differently from financial markets? The Economic Journal, Vol. 114, 223-246.

Li, Z., Zhou, S., Choubey, S. \& Sievenpiper, C. (2007). Failure event prediction using the Cox Proportional Hazard Model driven by frequent failure signatures. IIE Trans., vol. 39, no. 3, 303-315.

Lunde, A., Timmermann, A., \& Blake, D. (1999). The hazards of mutual fund underperformance: A Cox regression analysis. Journal of Empirical Finance, 6, 121-152. 
Marginson, D. (2010). Market ineffîciency in person-to-person betting: Examining 'known loser' insider trading on the exchanges. Southern Economic Journal, 76(4), 932-952.

McBride, T.A., Gorin, F.A., \& Carlsen, R.C. (1995). Prolonged recovery and reduced adaptation in aged rat muscle following eccentric exercise. Mechanisms of Ageing and Development, 83(3), 185-200.

Meyer, B. (1990). Unemployment insurance and unemployment spells. Econometrica, 58, 757-782.

McFadden, D. (1974). Conditional logit analysis of qualitative choice behavior. In P. Zarembka (Ed.), Frontiers in Econometrics (pp. 105-142). New York: Academic Press.

Moxnes E. (1998). Not only the tragedy of the commons: Misperceptions of bioeconomics. Management Science 44: 1234-1248.

Ongena, S. \& Smith, D. (2001). Empirical evidence on the duration of bank relationships. Journal of Financial Economics, 61, 449-475.

Ossimitz, G. (2002). Stock-flow-thinking and reading stock-flow-related graphs: An empirical investigation in dynamic thinking abilities. In Proceedings of the 2002 International System Dynamics Conference. May.

Ottaviani, M. \& Sørensen, P. N. (2008). The favorite-longshot bias: An overview of the main explanations, in Handbook of Sports and Lottery Markets, edited by D.B. Hausch and W.T. Ziemba, North-Holland, Amsterdam, 83-101.

Peel, D. (2009). Economics of Betting Markets. London and New York: Routledge.

Prentice, R.L., Williams, B.J. \& Peterson, A.V. (1981). On the regression analysis of multivariate failure time data. Biometrika, 68(2), 373-379.

Rooney, J.R. (1982). The relationship of length of race to fatigue and lameness in thoroughbred racehorses. Journal of Equine Veterinary Science, 2, 98-101.

Rossdale, P.D., Hopes, R., Wingfield-Digby, N.J. \& Offord, K. (1985). Epidemiological study of wastage among racehorses 1982 and 1983. Veterinary Record, 116, 66-69.

Sauer, R.D. (1998). The economics of wagering markets. Journal of Economic Literature, Vol. XXXVI, 2021-2064.

Russ, D.W., Lanza I.R., Rothman D. \& Kent-Braun J.A. (2005). Sex differences in glycolysis during brief, intense isometric contractions. Muscle Nerve 32, 647-655.

Russ, D.W., \& Kent-Braun, J.A. (2003). Sex differences in human skeletal muscle fatigue are eliminated under ischemic conditions. Journal of Applied Physiology. 94, 2414-2422.

Schnytzer, A. \& Shilony, Y. (1995). Inside information in a betting market. The Economic Journal, Vol. 105, 963-971. 
Schnytzer, A. \& Shilony, Y. (2002). On the timing of inside trades in a betting market. European Journal Of Finance, 8, 176-86.

Shane, S. \& Foo, M. (1999). New firm survival: Institutional explanations for new franchisor mortality. Management Science, 45, 142-159.

Smith, K.R. \& Zick, C.D. (1994). Linked lives, dependent demise? Survival analysis of husbands and wives. Demography, Vol. 31(1), 81-93, Springer.

Snowberg, E. \& Wolfers, J. (2010). Explaining the favourite-longshot bias: Is it risk-love or misperceptions? The Journal of Political Economy, 118(4), 723-746.

Stepanova, M., \& Thomas, L. (2002). Survival analysis methods for personal loan data. Operations Research. 50(2), 277-289.

Sterman, J.D. (1989). Modeling managerial behaviour: Misperceptions of feedback in a dynamic decision making experiment. Management Science, 35(3), 321-339.

Sterman, J.D. \& Diehl, E. (1993). Effects of feedback complexity on dynamic decision-making. Cambridge, MA: Sloan School of Management Massachusetts Institute of Technology.

Sterman J. D. (2000). Business dynamics: Systems thinking and modelling for a complex world. McGraw-Hill, Boston.

Sung, M. \& Johnson, J.E.V. (2008) Semi-strong form information efficiency in horse race betting markets, In: Hausch, D. and Ziemba, W. Eds., Handbook of Sports and Lottery Markets, 275-306.

Sweeney, L.B., \& Sterman, J.D. (2000). Bathtub dynamics: Initial results of a systems thinking inventory. System Dynamics Review, 16, 249-286.

Vaughan Williams, L. \& Paton, D. (1997). Why is there a favourite longshot bias in British racetrack betting markets? The Economic Journal, Vol. 107, 150-158.

Vaughan Williams, L. (1999). Information efficiency in betting markets: A survey. Bulletin of Economic Research. Vol. 51(1), 1-30.

Wei, L. J., Lin, D. Y. \& Weissfeld, L. (1989). Regression analysis of multivariate incomplete failure time data by modelling marginal distributions. Journal of the American Statistical Association, 84(408):1065-73.

Willett, J. \& Singer, J. (1995). It's a deja-vu all over again: Using multiple spell discrete-time SA. Journal of Educational and Behavioural Statistics, 20, 41-67. 